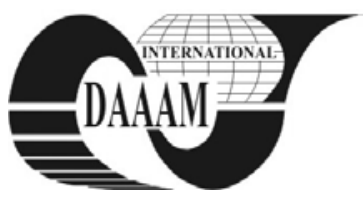

\title{
COMPARISON BETWEEN THE TRANSVERSAL DISPLACEMENTS FIELD OF THE LINEAR ELASTIC ROAD OF STRAIGHT BAR TYPE BEING IN FORCED VIBRATION OR IN REST
}

\section{BAGNARU, D[an] G[heorghe]; STANESCU, M[arius] M[arinel]; BOLCU, D[umitru]; MIRITOIU, C[osmin] M[ihai]; RIZESCU, S[abin] V[asile] \& DIACONU, I[lie]}

\begin{abstract}
In this paper we make a comparative study between the transversal displacements field of the rod (of straight bar type) of a R(RRT) mechanism (see Full \& all (1997)), kinematic element with linear elastic behavior, being in forced vibration (Fig.1) and the transversal displacements field of the same bar being in rest and simple supported. Finally, we compare the theoretical and experimental obtained results

Key words: vibration, $R(R R T)$ mechanism, linear elastic rod, transversal displacements field
\end{abstract}

\section{INTRODUCTION}

Until now, no comparative studies were made between transversal displacements field of a linear elastic rod being in vibration and respectively in rest. Through the obtained results, we suggest a novelty in the literature, exactly, we made the comparisons in same conditions, considering zero the initial ones when the bar is in rest as in the case of connection rod mechanism.

It is observed that the transversal displacement amplitudes from the resting linear elastic rod are lower than those from the case of linear viscoelastic rod of connection rod mechanism. In the future studies, we want to analyze the same problem, only that the elastic rod will be subdued to random vibrations.

\section{THEORETICAL RESULTS}

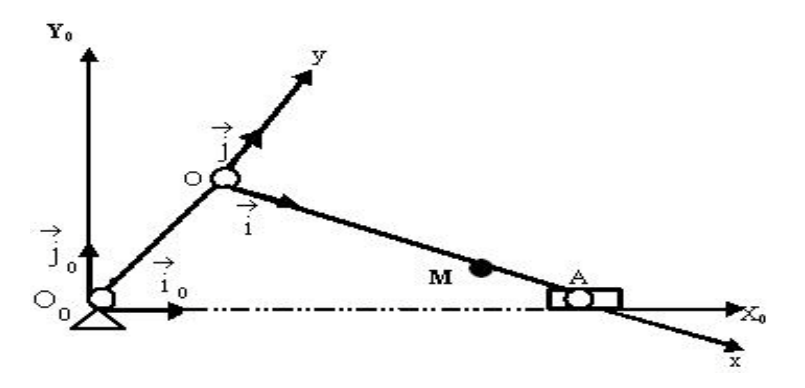

Fig. 1. R(RRT) Mechanism

In the case of a resting bar, if we impose the next aditional conditions:

- $\quad$ the cancellation on kinematical parameters;

- considering only the transversal vibrations;

neglecting inertia rotation,

we obtain that equation (see Buculei \& all (1986) Băgnaru \& all (1997), Băgnaru \& all (2009)).

$$
\begin{aligned}
& {[L]\{u\}+\rho \cdot A \cdot\left[\begin{array}{cc}
-1 & 0 \\
0 & 1
\end{array}\right]\left\{a_{0}\right\}+\rho \cdot A \cdot x \cdot\left\{\omega^{2} ; \varepsilon\right\}^{t}+} \\
& +\left[\begin{array}{cc}
1 & 0 \\
0 & -1
\end{array}\right]\{f\}+\left\{0 ; \frac{\partial m}{\partial x}\right\}^{t}=\{0\}
\end{aligned}
$$

becomes

$$
E I \cdot \frac{\partial^{4} u_{2}(x, t)}{\partial x^{4}}+\rho \cdot A \cdot \frac{\partial^{2} u_{2}(x, t)}{\partial t^{2}}-f_{2}=0
$$

\section{DISPLACEMENTS FIELD}

Considering homogenous the initial conditions, we apply the unilateral in relation with time Laplace transform to equation (1) and the sine finite Fourier transform. An algebric equation results having the solution:

$$
\tilde{u}_{2, S}^{*}(n, t)=\frac{f_{2}\left[1+(-1)^{n+1}\right]}{\alpha_{n} t\left(\rho A t^{2}+E I \alpha_{n}^{4}\right)}
$$

Finally, by inversing the two integral transforms in relation (2), the transversal displacements results, having the form of a time and position function, in the case of a simple supported linear elastic bar, being in rest, actioned by a constant force $f_{2}$, is given by the relation

$$
\begin{aligned}
& u_{2}(x, t)=u(x, t)=\frac{2}{L} \cdot \sum_{n=1}^{\infty}\left\{\frac{f_{2}\left[1+(-1)^{n+1}\right]}{E I \alpha_{n}^{5}} .\right. \\
& \left.\cdot\left[1-\cos \left(\alpha_{n}^{2} \sqrt{\frac{E I}{\rho A}} t\right)\right]\right\} \sin \left(\alpha_{n} x\right) \\
& \text { where } \alpha_{n}=\frac{n \pi}{L} .
\end{aligned}
$$

In Bagnaru (2005), in the first approximation, it was obtained the transversal displacement field, in the case of free vibrations of OA rod of R(RRT) mechanism from figure 1 having the form of time and position function

$$
\begin{gathered}
u_{2}^{(1)}(u, t)=u(x, t)=\frac{2 b}{L} \cdot \sum_{n=1}^{\infty} \frac{1}{b_{n}}\left[\left(\sum_{j=1}^{4} b_{j, n}\right) \sin \left(\omega_{0} t\right)+\right. \\
\left.+\left(b_{5, n}+b_{6, n}\right) \sin \left(2 \omega_{0} t\right)+\left(\sum_{j=1}^{4} c_{j, n}\right) \sin \left(\omega_{n, 2} t\right)\right] \cdot \\
\cdot \sin \left(\alpha_{n} x\right)
\end{gathered}
$$

In order to make the suggested comparisons in similar conditions, there have been considered zero the initial conditions in the resting bar case as in the case of rod from the connecting rod mechanism, it was necessary to suppose the simple supported bar as being subdued to slight perturbations having a constant force form $\mathrm{f}=0,125[\mathrm{~N}]$.

Next, taking the numerical application as an example where

$$
E=2,1 \cdot 10^{11}\left[\frac{N}{\mathrm{~m}^{2}}\right] ; L=1[\mathrm{~m}], b=0,04[\mathrm{~m}], \rho=7800\left[\frac{\mathrm{kg}}{\mathrm{m}^{3}}\right] \text {, }
$$


$h=0,005[\mathrm{~m}]$, it is observed that transversal displacements amplitudes from the case of a resting linear elastic bar subdued to transversal vibrations are lower than those from the case of a linear elastic rod part of the connection rod mechanism as in tab. 1.

\begin{tabular}{|c|c|c|}
\hline Bar type & OA rod & Resting OA bar \\
\hline $\begin{array}{c}\text { Transversal } \\
\text { displacement }[\mathrm{mm}] \\
u(x, t) \epsilon\end{array}$ & {$[-0,15 ; 0,15]$} & {$[-0,1 ; 0,1]$} \\
\hline
\end{tabular}

Tab. 1 . The transversal vibration amplitudes from the two cases

\section{EXPERIMENTAL TESTINGS}

The used technique for the experimental study is compound of Spider 8 software, a notebook, and the signal conditioner Nexus 2692-A-0I4. The recordings were made with a sample frequency of 2400 samples/seconds/ channel for a period of $7 \ldots 15 \mathrm{~s}$.

We followed the next procedure :

- there was set an acting frequency in the gap of $1 . .4 \mathrm{~Hz}$;

- the data aquisition was started and the acting motor was turned on;

- after the aquisition, the results vere visualised and stored in ASCII files, with suggestive names, having on the first column the time and the recorded parameters on the others: Time (s); Crs (mm); Dpl1 (mm); Dpl2 (mm); Dpl3(mm).

The file names are: Material type \& Loading direction \& Loading order, where Material type = M (metal); Loading direction $=\mathrm{O} / \mathrm{V}$ (horizontal, transversal, vertical); Loading order $=1,2, \ldots 12$.

The connecting rod system was acted by a three-phase motor AC power of $25 \mathrm{~kW}$ with constant speed 1500 [rpm], through a variator with friction, so that at the level of the connecting rod, there could be realised the variable speed in range 60-240 [rpm].

To determine the vibratory response, there were used three B \& K 4391 accelerometers mounted to 50 [mm] of the drive end, the middle rod and to $50[\mathrm{~mm}]$ by the end of the backstage operation, successively on vertical direction, and horizontaltransversal toward the plane for operating of the connecting rod.

In fig. 2 and 3 are presented the diagrams of variations in time of the transversal displacement in the case of linear elastic rod, part of the mechanism from fig. 1.

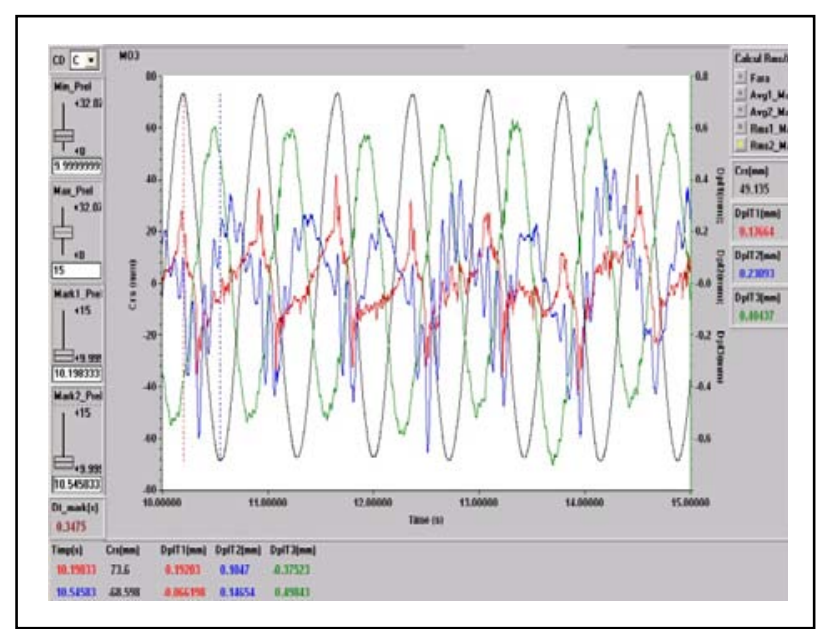

Fig. 2. The diagrams of variations in time of the transversal displacement

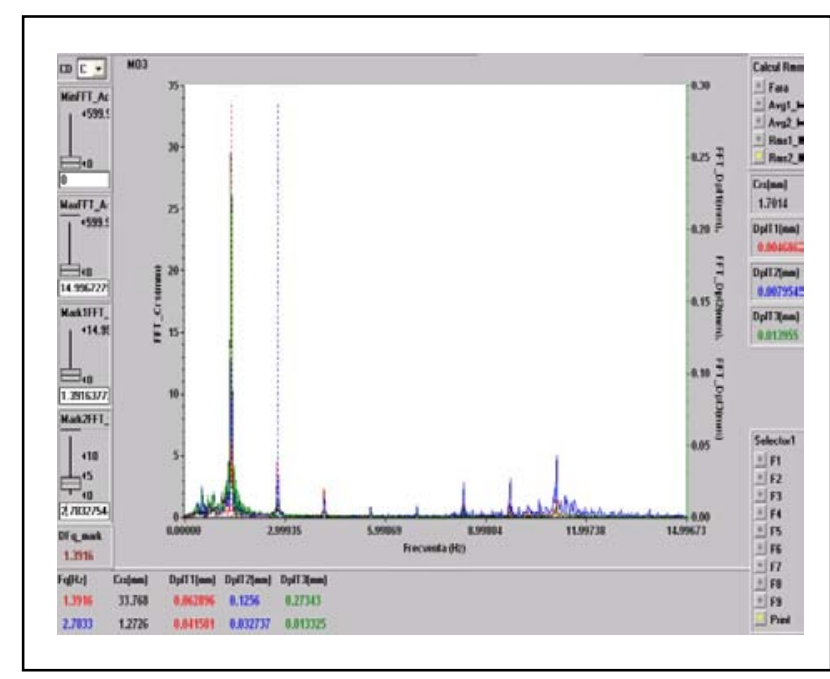

Fig. 3. The diagrams of variations in time of the transversal displacement

Calculating the error with the relation:

$$
\varepsilon=\frac{\left|u_{2}^{t}-u_{2}^{e}\right|}{u_{2}^{\max }}
$$

where $u_{2}^{t}$ and $u_{2}^{e}$ are the theoretical and experimental values of the displacement $\left(u_{2}^{\max }=\max \left\{u_{2}^{t} ; u_{2}^{e}\right\}\right)$, we obtained the errors $\varepsilon<10 \%$, which are allowed in technique, due to the clearances from kinematical couplings, and the vibrations transmitted through basis and approximate methods that we used.

\section{CONCLUSIONS}

The elements that were presented above show that the kinematic parameters of movement lead to increased vibration amplitudes, wherefore, it is necessary, as in the case of mechanisms design, to take into account the influence of kinematics parameters of the movement at the displacements caused by existing of the vibrations.

\section{ACKNOWLEDGMENT}

This work was partially supported by the strategic grant POSDRU/88/1.5/S/50783 (2009), co-financed by the European Social Fund - Investing in People, within the Sectoral Operational Programme Human Resources Development 20072013.

\section{REFERENCES}

Bagnaru, D. , Gh. , \& all, (2009) Influence of kinematic parameters on the deterministic vibrations of the linearelastic connecting rod, component of a rod lug mechanism, Annals of DAAAM, 20(1), p. 835-837, ISBN 978-3901509-70-4

Bagnaru, D.,(2005) The vibrations of kinematic elements, SITECH Publishers, Craiova, ISBN 973-657-854-2

Bagnaru, D., Rizescu, S., Bolcu, D., (1997), The vibrations of elastic systems, Didactic and Pedagogic Publishers, Bucuresti, ISBN 973-30-5907-2

Buculei, M., Băgnaru, D., Nanu, Gh., Marghitu, D., (1986), Calculus methods in the analysis of the mechanisms with bars, Scrisul Romanesc Publishers, Craiova

Fu, K.S., Gonzalez, R.C. \& Lee, C.S.G. (1997). Robotics, McGraw-Hill 